\title{
"Fit" for service: contrasting physician profiles and motivations for short-term medical missions and Médecins Sans Frontières
}

\author{
Paul H. Caldron
}

\begin{abstract}
Background: Physicians from wealthy countries often provide direct medical services in low- and middle-income countries either on a short-term or long-term basis, herein differentiated by the physician's source of income, rather than by time or mission specifics. Research data has accumulated in recent years on physician profiles and motivations for short- and long-term dimensions of physician commitment. This review provides some current insights on these physician pathways for transnational direct caregiving activities.

Objectives: Comparison is made of US physician profiles and motivations for short-term medical missions and those of long-term medical missions, specifically from Médecins Sans Frontières (MSF) for which comparative information is available.

Conclusions: Current literature suggests that short-term medical mission physicians tend to be older, married males while MSF physicians are more gender-balanced, younger, and less woven into the traditional domestic medical system. Altruism and idealism are shared motivations. MSF long-term physicians may be more risk tolerant. The two dimensions are not competitive for the hearts and minds of physicians, but rather complementary.
\end{abstract}

Keywords: Short-term medical missions, Médecins Sans Frontières, Physician profiles, Motivations, Humanitarian medicine

\section{Background}

Defining the profiles and motivational characteristics of participants in humanitarian medical care may influence recruitment and investment strategies of policy makers. In addition, having reference models may assist current or potential participants in reconciling their own compassionate yearnings and may be valuable in supporting their decision to act. The diverse array of actors and dimensions compels that the study of humanitarian care be parsed into segments that ultimately reconnect to form a body of relevant knowledge. Such a composite, though ever evolving, may inform effective implementation strategies and utilization of resources. Among the myriad of skilled personnel required in effective and sustained direct medical interventions, physicians remain essential, so the features of physician participation are a

Correspondence: pcaldron@global.t-bird.edu

University of Arizona College of Medicine, Phoenix, AZ, USA good starting point. This review approaches characterization of physician participation in humanitarian medical care by comparison of paid and unpaid private sector participation that tends to align with short-term and long-term deployments. Some important variations and commonalities in profiles and motivations emerge that are relevant to both policy makers and participants.

Participation of physicians from high-income countries in direct overseas humanitarian healthcare in low- and middle-income countries varies with respect to duration of commitment [1]. Long term commitments are exemplified by Medicines Sans Frontières (MSF; Doctors Without Borders), widely recognized through its work in slow disasters of conflict, epidemiologic crises, and famine. The less visible dimension of humanitarian medical care is short-term medical missions (STMMs). These commitments for few days to a few weeks are performed by physicians who are gainfully engaged in their own 
practices at home. In this paradigm, physicians go, sometimes alone and more often accompanied by ancillary staff, to poorer countries, where they provide direct medical or surgical care without compensation to those who have little access to medical care related to their poverty. Survey and narrative data have accumulated in recent years that allow an initial comparison of profiles and motivations of physician participants in STMMs from the US and long-term medical missions (LTMMs), specifically from MSF. The aim of this review is to coalesce information from multiple sources that may provide for a comparative description of physician profiles and motivations for STMMs and LTMMs. The utility of this comparison is to provide an insight into the pathways physicians may choose in overseas direct caregiving.

Considerable overlap and confluence exists between STMMs and LTMMs from the perspective of time, mission objectives, and mission execution. The distinction in this analysis emanates from the financial perspective of the physician participant rather than specific time parameters, the mission, or mission organization. STMMs allow for the maintenance of a continuous domestic practice and LTMMs do not. Concordantly, STMMs are uncompensated, whereas LTMMs generally require a stipend of some sort for the physician to participate. Because the most discoverable information to date regarding physician profiles and motivations for LTMMs is from MSF, the contrast will be developed upon data on STMMs from the US and from MSF LTMM physicians. The Nobel Peace Prize-winning organization MSF is perhaps the most recognizable long-term option for which information is accessible and current [2].

Several dimensions of humanitarian healthcare are excluded from this comparison. The acute medical component of international response to geophysical disasters generally takes the form of civil military action financed and coordinated through and among governmental agencies, and is not included in this comparative discussion of physician volunteering. MSF and STMMs are purely private sector initiatives, wholly disconnected from government. Along with US military humanitarian medical relief, this comparison excludes long-term expatriate medical efforts directly supported by the US government such as USAID President's Emergency Plan for Aids Relief (PEPFAR) and the Peace Corps Global Health Service Partnership wherein physicians receive stipend support for capacity building programs. Whereas those civilian federal programs show promise in their early years towards narrowing disparities in global health, information on demographics and motivations of physicians does not yet appear to have been systematically evaluated. Further, this essay compares motivational characteristics of physicians engaged in direct surgical or medical care of the injured or sick, and does not address these aspects of physicians that focus on public health measures. Unquestionably, nursing and ancillary medical personnel make enormous contributions to humanitarian and global health; for the sake of manageability, this review only examines and compares information on physicians licensed to practice the full scope of medicine (MD and DO degrees, or US equivalent).

This topical review is not an original systematic literature review nor does it represent new primary research data. Rather, the evidence, as referenced throughout the review, is drawn from several sources. These include the author's prior published systematic literature review, numerical data from a primary demographic and economic survey of physicians, and narrative data on physician participation in STMMs. Comparative information is coalesced from available online sources regarding MSF and from the MSF Foundation Centre de réflexion sur l'action et les saviors Humanitaires (CRASH), including personal communications. Organizational perspectives that may influence actors in humanitarian medicine are supported by key referenced publications of the current decade.

\section{Review of the dimensions, physician profiles and motivational aspects of STMMs and LTMMs (MSF) STMM background}

Over the past 4 decades, the literature provides many reports on STMMs that are mostly of a reflective nature, relating the perceived benefits to volunteers and recipients as well as the potential pitfalls of the activity, including lack of adequate follow-up in care and disruption of local healthcare and capacity [3,4]. Only in the past 10-15 years have articles accumulated with operational or ethical guidelines and instructions, designed to promote effectiveness and reduce the risks of such non-continuous, foreign medical presence $[5,6]$. Relatively little evidence has been published about why physicians go, what types of physicians go, how many go, and how much is spent on this activity $[7,8]$.

STMMs are increasing, driven mostly by physician-tophysician interaction, and facilitated in the digital age by the ease of identifying a myriad of opportunities in online searches $[7,9]$. On average, in the decade 2004 to 2013, as many as $100 \mathrm{~K}$ US physicians annually may have performed at least one STMM [7].

US physicians spend about $\$ 4 \mathrm{~K}$ per trip in direct costs, and experience about $\$ 8 \mathrm{~K}$ in opportunity costs per trip. If one combines physician costs with direct costs for up to 4 ancillary personnel per physician on a conventional traveling team, the composite annual costs from the US for STMMs may reach well over $\$ 3 \mathrm{~B}$ annually, two-thirds of that comprised of direct costs by participants [7]. Travel vaccines, disease prophylaxis costs, and the value of donated medical and surgical 
goods were not included in these calculations. This is 810 fold a previously-published estimation from 2008 [10]. This amount is material when benchmarked against formal tranches of US foreign aid disbursement reported in 2014: US aid to Afghanistan (\$3.1B), contributions to International Organizations and Peacekeeping Activities (\$3.7B), Consular Affairs and the Border Security Program (\$2.8 B), Humanitarian Assistance (\$4.1B), and the Global Health Initiative (\$8.3B) [11]. The estimated number of working days that US physicians collectively expended on STMMs in 2012 approached 5800 full-time equivalents, a curious fact in an era when the US physician shortage is estimated in the tens of thousands [7].

The description of STMMs and the physicians who carry out these unregulated, non-government-sanctioned activities may create the impression of a fragmented and inefficient phenomenon. At the same time, it is reasonable to assume that the physicians who participate are not only intelligent and well organized, but insightful, self-reflective, and clever in matching an inclination for humanitarianism to the opportunities that exist for them in the context of the full scope of their lives. The results are viewed by physicians as positive both for the receivers of medical care and for themselves $[9,12]$.

\section{MSF background}

Broadly speaking, personal risk may be higher in LTMMs, whether by exposure to open conflict, civil unrest, uncontrolled epidemic, or an unsafe geophysical environment. MSF, as the operational comparator, purposely goes to areas where populations are at risk from conflict, whereas STMM volunteers typically do not, and may be restricted from travel to conflict areas by the US State Department.

Doctors and journalists were the founders of MSF in 1971 with the intention to treat people subjected to conflict, famine and natural disasters, and simultaneously call attention to their suffering and its geopolitical causes. In her seminal article on the characteristics of those who are attracted to and remain with MSF, Siméant described the socio-cultural milieu that witnessed the ascent of MSF during a time of political and religious crisis in France in the 1970s that created a vacuum for people longing for social reform [13]. Siméant's French language narratives are enhanced and supported by her references to the zeitgeist of the epoch. Leftleaning parties were beginning to lose power. By the early 1980s, humanitarian vocations were viewed as honorable, and the humanitarian posture was considered both moral and politically neutral or centrist. Media increasingly extolled the humanitarian activity of organizations like the Red Cross. Pro-humanitarian youth literature proliferated as did the influx of funding from public and private sources for humanitarian groups.
Humanitarian zeal, along with environmental activism, became the prevailing inclination, and seemed to substitute for political activism.

MSF has grown and been sustained by effective marketing, the impact of which has resulted in a faithful five million individual and organizational donors worldwide who provide $90 \%$ of revenues [14]. According to online annual reports, global expenditures by MSF in 2015 reached $\$ 1.3 \mathrm{~B}$, underwritten with a US component contribution of $\$ 0.38 \mathrm{~B}$ [14].

Skilled health care personnel make up about $65 \%$ of the roughly 30,000 deployed MSF staff at any given time [15]. Approximately $26 \%$ of skilled healthcare staff is physicians of which an estimated 7\% is from international sources and the remainder is locally sourced. In 2014, an estimated 115 US physicians were deployed [16].

Physicians with MSF are generally required to commit to a 9-12-month period of service at a time. Exceptions include surgeons, anesthesiologists and obstetriciangynecologists who sometimes are accepted for period commitments of 6-12 weeks [16].

Physicians' billeting and meals are provided communally or by per diem allowance. Starting pay, according to the MSF website, comes in the form of a \$1731 monthly stipend that may increase with accumulated service time and level of responsibility [16]. Although incomes are relatively low in MSF compared to fulltime domestic practice, one can make a living and accumulate savings. Full health insurance is provided along with other benefits.

\section{Contrasting physician profiles and motivations Data on STMM physicians}

Multivariate regressions from survey data indicate that being a surgeon, anesthesiologist or pediatrician predicts STMM participation over practicing other areas of medicine [8]. Being in the oldest of three age groupings (56-73 years) and being married also independently predict participation. The one-time Physicians' Giving Back Survey indicated that nearly twice as many males as females participate in STMMs. Descriptively, STMM physicians tend to have few or no children in the home at the time of their STMMs, and to have an earned income that is somewhat less that average among their colleagues. Lesser participation among those of higher annual incomes may suggest, among other possibilities, that the increasing opportunity cost of income foregone while away may act as a constraint on participation. This interpretation resonates with findings that arose during physician interviews that unveiled a set of personality traits perceived of repeat participants that begins with unselfishness [9]. Flexibility, referring to the ability to perform effectively in labile or technology-limited circumstances, seems a pre-requisite. The traits profile also 
included high self-confidence and strong personal ethics, as well as tolerance for arduous and less sanitary conditions. Building on that demographic and personality background, these narratives indicated that the key drivers of motivation, and hence the rewards sought by physicians, include the satisfaction of helping others in difficult circumstances, the appreciation felt from patients and communities, teaching and the physicians' own learning experiences, and a sense of renewal. Faceto-face experiences with patients and the legacy effect of teaching evoke a desire to repeat.

In contrast, religious affiliation, some elements of religiosity, and the desire to project a favorable image of America were not dominant in the choice to participate. Similarly, the difference in medical philosophy embodied in the two consummate medical degrees available in the United States, MD and DO, did not differentiate participants and non-participants. Half of US physician subjects in the cited narratives identified influences of family or events while growing up as instrumental in pre-disposing them to take part in STMMs, and most of these acknowledged role models in their lives [9].

Most STMMs by US physicians take place in Latin America, not because of pre-existing ethnic or national ties, but rather for reasons related to its proximity. Martiniuk et al. found similar hemispheric ties between the UK and Africa, and Australia and Southeast Asia/ Oceania. Canada departs from the pattern with its predominant focus on Africa, perhaps connected to its allegiance to the British monarchy and colonial history [3].

\section{Data on MSF physicians}

Comparing the demographic and professional characteristics of STMM and MSF physicians is frustrated by the paucity of such data catalogued by MSF human resources coordinators. For MSF international physicians (those that travel to another country), the male to female ratio is roughly equal, although this data does not demarcate physicians from paramedical personnel [15]. The mean age for all MSF medical personnel was 40.3 years. Seventy-two percent of travelling medical personnel comes from Europe or North America. No data is collected for race, religion, marital status, children at home, or most frequent specialties (personal communications: Fabrice Weissman, Fondation MSF Centre de réflexion sur l'action et les savoirs humanitaires (CRASH) and Pierre Monnier, Fondation MSF Human resources, 2016).

From a collage of personal narratives, Siméant portrays the MSF physician as disengaged from traditional medical practice [13]. This disengagement seems related in part to constrained availability of employment and societal devaluation of the medical profession. Another part of the disengagement, to paraphrase Siméant, is the attraction of the honor of activism and a virile flaunting of one's courage and noble risk-taking. At the time of MSF's birth, a similar disengagement from politics ensued, drawing would-be zealots from both the right and left of the political spectrum to cohabitate in the witness of famine and genocide. Humanitarian medical practice would allow one to be more than just a doctor, and one could remain an honorable doctor even if the work was intermittent. The blending of participants from diverse backgrounds inclusive of foreigners and those with Jewish ancestry allowed MSF to flourish from its French foundations, yet as a non-nationalistic movement. From these beginnings, the factors of challenge, risk, and adventure have served the retention of volunteers, creating somewhat of a veritable "risk aristocracy".

Roderick Wong, a Canadian psychologist, in his text on biobehavioral concepts of motivation, cites the description by Leyton and Locke of MSF personnel in Rwanda during the genocide of 1996 [17, 18]. In that MSF staff seemed to be able to ignore the massive risk about them, the work disconnects them from the minor irritations and "mindlessness of modern life". Leyton and Locke opine that "self-actualization" à la Maslow's hierarchy of needs may thereby figure into motivation of MSF staff [19]. As with extreme sports and combat itself, a similar clarity of mind may arise from such adrenalinelaced consciousness and focus.

The backgrounds of physicians from the Siméant interviews included several common threads, beginning with having been in scouting and other forms of early socialization like summer camp, competitive sports, military, and monastic life. Though not failures in education, schooling was not high priority for many. Often, those attracted to humanitarian careers have had difficulty as adult professionals, not with their knowledge or skills, but rather with integrating comfortably into the professional establishment. Professional humanitarian organizations identify and recruit such individuals. Exposure to discrimination, family trauma that led to unexpected responsibility at a young age, and having a hero or social militant figure in the family were repeating themes. Long-term expatriate humanitarian careers are commonly triggered after the death or separation from a significant other. Finally, Siméant calls attention to the advantages of short-term volunteerism since career expatriate humanitarian physicians may find their core skills becoming arcane, and experience psychosocial difficulties with re-entry into their native social structure.

Siméant interviewed mainly volunteers working in conflict settings. In fact, about half of MSF missions now are so-called "mid-term/long-term programs" addressing chronic issues such as the HIV epidemic or high mortality from malnutrition and infectious disease among children in "stable" contexts. Taking this dimension of MSF into 
consideration, the differences between STMM and MSF volunteers' motivations and profiles may be less acute, although no data is available (personal communication: Fabrice Weissman, Research Director at MSF Foundation Centre de réflexion sur l'action et les saviors Humanitaires $(\mathrm{CRASH})$ ). The terms of these programs generally remain impractical for physicians in domestic practice.

Found within the blog section of the MSF-USA webpages, testimonials bear further insights on a blend of four motivations: 1. escape from a past life or current social situation, 2. adventure and challenges, 3. money (though modest, it can be steady work), and 4. idealism, the hope to be a positive force for humanity [20]. Jobanputra herein contends that all international aid workers demonstrate escapist tendencies, along with adventurism, and concedes that emotional baggage weigh into motivations. Nonetheless, he defends the idealism component as a mechanism of consciously choosing how to influence others. Responders to Jobanputra's blog post have expressed that the calculation of motivation did not matter provided that results were seen during the project, and that the hard work and setbacks will dispense with the romantic aspects very quickly.

\section{Influence of organizations on physician motivations}

NGOs with which US STMM physicians choose to work, if any, are selected based on varying personal criteria, or simply who has invited them. STMM narrative subjects rarely saw in their own motivations the projection of nationalistic influence, and gave no inkling that selection of organizations with which to work had any basis in secondary messages, except, at times, evangelical [9]. Mendoza suggests that the lack of access to medical care and the suffering it provokes is grounded in market failure, and therein lies the impetus for STMM activity as a civil society response [21]. Lasker found nothing in her dual methodology study on STMM-sending organizations to suggest that their objectives include drawing attention to the failures of governing regimes or market mechanisms [22, 23]. The non-medical objectives of organizations that sponsor STMMs, including evangelism, education, fund raising, recruitment, reputation enhancement, research, and nurturing future leadership are non-nationalistic and rooted in the private sector.

MSF has been on display as a case study on organizational motivation in numerous management texts and symposia [17, 24, 25]. The non-medical half of MSF's core objectives involves the signaling of injustice towards the oppressed and displaced, and as Siméant implies, might be a motivation for physicians [13].

\section{Conclusion: The long and short of it - whatever fits}

Though a structured qualitative analysis of motivation of comparative cohorts has not been performed, several parallel themes emerge from what has been heretofore published in various media. Demographic profiles hold the most distinction: whereas STMM physicians tend to be older, male, and married, MSF physicians are younger, more gender-balanced, more risk-tolerant, and less woven into the traditional domestic medical system. The most obvious driver that joins physicians of MSF and STMMs on the same platform is the underlying element of altruism, used herein as interchangeable with idealism. This altruism must endure, or else the hardships of both STMMs and MSF field deployment are too discouraging for one to continue. Flexibility, as an intrinsic source of resilience and effectiveness, is also essential. Until global health inequities converge sufficiently, strategies to identify and sustain that altruism and flexibility should be elucidated and leveraged.

The economic comparisons of MSF and STMM participation relevant to personal motivation are moot since the former endeavor is compensated while the latter is pro-bono, notwithstanding that STMM participation preserves the opportunity for a more lucrative medical career. At a composite level, though fragmented, the economic inputs to STMMs from the US alone are more than double the resources expended annually by MSF. The number of physicians participating in STMM sorties dwarfs the cohort inclined to undertake the total commitment and risk in MSF. Though less recognized, the relative magnitude of the STMM inputs cannot be overlooked. One can only speculate about the uncounted lives saved and disability adjusted life years saved in STMMs in relative proportion to the relief efforts of MSF as such impact data is heretofore unavailable.

In the Nobel acceptance address on behalf of MSF, James Orbinski linked the mindset of both short-term and long-term medical volunteers, capturing the essence of motivation tied to the moment of patient encounters [26]:

"Despite the grand debates on world order, the act of humanitarianism comes down to one thing: individual human beings reaching out to their counterparts who find themselves in the most difficult circumstances."

Physicians involved in both long-term and short-term humanitarian care endeavors go beyond epidemiological remedies to one-on-one actions, and in doing so, occupy the same space at the effector end of the implementation process. Each of these humanitarian medical pathways presents its own sources of friction to the professional: cost and practice stress on the STMM road, and perhaps some professional stagnation on the MSF road. The acuity of the MSF LTMM response demands continuous activation and forward planning. It succeeds on the rails of tapping into a world of donors who care, and physician participants who are less encumbered by the circumstances of lives that hold them to other 
commitments. In contrast, STMM physicians fit their resolve for altruism into lives fully integrated into the domestic social fabric and its continuous demands. The two dynamics are not competitive for the hearts and minds of physicians, but rather complementary. As Siméant insinuates, humanitarian medical work is a matter of coupling of the individual physician life circumstances to differing venues for the same purpose [13]. As in narratives indicating that direct interactions with patients in STMMs evoke the desire to repeat, Dr. Mutwali Adam of MSF notes the reinforcing effect of saving a life during conflict. He finds resonance with a passage from the Quran: "If anyone saved a life, it would be as if he saved the life of the whole people" [27].

This review has focused on backgrounds of STMM and LTMM dimensions and the profiles and motivations of physician participants and provides insights for policy and research communities on physician humanitarian work. Future research on the profiles and motivations of physicians, as well as other health professionals, could be enhanced through national or international registries of participants, capturing demographics and records of humanitarian service deployments. Through research fostered by groups such as Partners in Health and the Consortium of Universities for Global Health, the future holds promise for the development and implementation of measures of impact and improved effectiveness of these dimensions $[28,29]$. As the knowledge base on effectiveness builds, new insights are likely to evolve on the physician subset destined to be involved in these efforts.

\section{Abbreviations \\ CRASH: Centre de réflexion sur l'action et les savoirs humanitaires - Fondation MSF; DO: Doctor of osteopathic medicine; LTMM: Long-term medical mission; MD: Medicus Doctorus - medical doctor; MSF: Médecins Sans Frontières (Doctors Without Borders); NGO: Non-governmental organization; PEPFAR: President's emergency plan for aids relief; STMM: Short-term medical mission; USAID: United States Agency for International Development}

\section{Acknowledgements \\ The author thanks Fabrice Weissman, Research Director at MSF Foundation Centre de réflexion sur l'action et les saviors Humanitaires (CRASH), for his critical review of the manuscript for general accuracy regarding the insights on MSF. The author also thanks Marc Bergevin, PhD for technical translation of French language reference text to English language.}

\section{Funding}

None.

\section{Availability of data and materials}

Not applicable.

\section{Authors' contributions}

PC was completely responsible for the manuscript design and writing.

\section{Authors' information}

Portions of this essay are adapted from the doctoral dissertation: The Tacit Bargain in Short-Term Medical Missions: Why US Physicians Go and What It Costs. Caldron, PH. 2016 Boekenplan, Maastricht. ISBN 9789086664078.

Ethics approval and consent to participate Not applicable.
Consent for publication

Not applicable.

\section{Competing interests}

The author declare that he has no competing interest.

\section{Publisher's Note}

Springer Nature remains neutral with regard to jurisdictional claims in published maps and institutional affiliations.

Received: 6 July 2017 Accepted: 27 August 2017

Published online: 12 September 2017

References

1. World Bank Country and Lending Groups. Country Classification. https://datahelpdesk.worldbank.org/knowledgebase/articles/906519-worldbank-country-and-lending-groups. Accessed 21 June 2017.

2. Solholm R. Nobel Peace Prize awarded to Doctors without Borders (Medecins Sans Frontiers). Norway Post, Saturday, 16 January. 1999.

3. Martiniuk ALC, Manouchehrian M, Negin JA, Zwi AB. Brain gains: a literature review of medical missions to low and middle-income countries. BMC Health Serv Res. 2012;12:134. doi:10.1186/1472-6963-12-134.

4. Lasker JN. Hoping to help: the promises and pitfalls of Global Health volunteering. Ithaca: Cornell University Press; 2016.

5. Caldron PH, Impens A, Pavlova M, Groot W. A systematic review of social, economic and diplomatic aspects of short-term medical missions. BMC Health Serv Res. 2015;15(1):380. doi:10.1186/s12913-015-0980-3.

6. Van Tilburg C. Controversies in medical aid to developing countries: balancing help and harm. Int Health. 2015;7(3):147-8. doi:10.1093/inthealth/ ihv028.

7. Caldron PH, Impens A, Pavlova M, Groot W. Economic assessment of US physician participation in short-term medical missions. JGlobalization\& Health. 2016;12(45):1-10. doi:10.1186/s12992-016-0183-7.

8. Caldron P. Impens A, Pavlova M, Groot W. Demographic profile of physician participants in short-term medical missions. BMC Health Serv Res. 2016;16(682):1-10. doi:10.1186/s12913-016-1929-x.

9. Caldron PH, Impens A, Pavlova M, Groot W. Why do they care? Narratives of physician volunteers on motivations for participation in short - term medical missions abroad. Int J Heal Plann Mgmt. 2016;2016(1-21):1-21. doi:10.1002/hpm.2402

10. Maki J, Qualls M, White B, Kleefield S, Crone R. Health impact assessment and short-term medical missions : a methods study to evaluate quality of care. BMC Health Serv Res. 2008:8:1-8. doi:10.1186/1472-6963-8-121.

11. Kerry J. Highlights of the Department of State and U.S. Agency for International Development Budget. https://www.usaid.gov/sites/default/ files/documents/1869/FY2014Highlights_FactSheet.pdf. Accessed 31 Dec 2014. Published 2014

12. Van Tilburg CS. Attitudes toward medical aid to developing countries Wilderness Env Med. 1995;6(3):264-8. http://www.wemjournal.org/article/ S1080-6032(95)71062-6/pdf?showall=true=.

13. Siméant J. Entrer, rester en humanitaire: des fondateurs de msf aux membres actuels des ong médicales françaises. CAIRNINFO Press Sci Po. 2001;51(1):47-72. doi:10.3917/rfsp.511.0047.

14. Médecins Sans Frontières Financial Report 2015. www.msf.org. Accessed 24 Dec 2016.

15. IDRH platform. MSF Human Resources Indicators 2014 - Report to the International General Assembly; 2015.

16. Médecins Sans Frontières - Doctors Without Borders - USA. Web page. http://www.doctorswithoutborders.org/about-us/msf-leadership/us-staff. Published 2016. Accessed 24 Dec 2016.

17. Wong R. Motivation - a Biobehavioural Approach. First. Cambridge: Cambridge University Press; 2000

18. Leyton E, Locke G. Touched by fire: Doctors without Borders in a third world crisis. Toronto: McClelland and Stewart, Ltd; 1998.

19. Maslow A. Motivation and personality. First. Harper and Brothers; 1954

20. Jobanputra K. Motivation. MSF-USA Blog. http://blogs.msf.org/en/staff/ blogs/frombunia/. Published 2010.

21. Mendoza RL. Public health policy and medical missions in the Philippines: the case of oral-facial clefting. Asia Pac J Public Health. 2009;21(1):94-103. doi:10.1177/1010539508327028. 
22. Lasker JN. Global Health volunteering; understanding organizational goals. Volunt Int J Volunt Nonprofit Organ. 2015. doi:10.1007/s11266-015-9661-4.

23. Lasker JN, Rozier M, Compton B. Short-term medical mission trips: Phase I. Research findings-practices \& perspectives of U.S. Partners. St. Louis: Catholic Health Association of the United States. 2014.

24. Griffin RW. Fundamentals of Management. 5th ed. (Johnson L, Perez J, Burns F, eds.). Boston: Houghton Mifflin Company; 2008.

25. Mort K. Putting Ideals into Practice: The Role of Motivation and Employee Engagement in Doctors Without Borders. In: 2015 Global Talent Management Conference. New York City: Human Capital Institute: The Global Association for Strategic Talent Management; 2015. http://www.hci. org/lib/putting-ideals-practice-role-motivation-and-employee-engagementdoctors-without-borders. Accessed 28 Feb 2016.

26. Orbinski J. Médecins Sans Frontières - Nobel Lecture. In: Oslo: The Nobel Foundation; 1999. doi:Nobelprize.org. Nobel Media AB 2014.

27. Adam M. Darfur: "Every Time You Are Able to Save a Patient, It Gives You the Motivation to Save Another Life." MSF-USA website. http://www. doctorswithoutborders.org/newsstories/. Published 2013. Accessed 23 Feb 2015.

28. Farmer P, Kim JY, Kleinman A, Basilico M, editors. Reimagining Global Health: an introduction. 1st ed. Los Angeles and Berkley: University of California Press; 2013.

29. Consortium of Universities for Global Health. http://www.cugh.org/. Accessed 21 June 2017.

\section{Submit your next manuscript to BioMed Central and we will help you at every step:}

- We accept pre-submission inquiries

- Our selector tool helps you to find the most relevant journal

- We provide round the clock customer support

- Convenient online submission

- Thorough peer review

- Inclusion in PubMed and all major indexing services

- Maximum visibility for your research

Submit your manuscript at www.biomedcentral.com/submit 